\title{
ИMEHА. ПОРТРЕТЫ
}

УдК 1(47)"191"(093.3)

ББК 87.3(г)53-689ю14

DOI 10.25281/2072-3156-2019-16-1-62-71

\section{А.В. ЛОМОНОСОВ}

\section{О ЛИТЕРАТУРНОМ ТЕРРОРЕ (ПО МАТЕРИАЛАМ ЧЕРНОВИКОВ И НЕИЗДАННЫХ СТАТЕЙ B.B. PO3АHOBA)}

\section{Алексей Васильевич Ломоносов,}

Российская государственная библиотека,

Центр исследования проблем развития библиотек в инорормационном обществе,

сектор изучения особо ценных фондов,

научный сотрудник

Воздвиженка ул., д. 3/5, Москва, 119019, Россия

кандидат исторических наук

ORCID 0000-0001-9755-8649; SPIN 3533-2784

E-mail: Iomonosov-1962@yandex.ru

Реферат. $B$ статье представлены взгляды розановедов на спеиифику ведения В.В. Розановым литературных дискуссий. Подиеркнуты особенности полемики мыслителя с П.Б. Струве и его соратниками о границах партийных рамок в ходе публиных заявлений в коние 1910 - начале 1911 года. В означенной теме были отмечены наиболее яркие детали споров. Это подтверждено изитированием различных черновых редакций рукописных материалов из архива В.В. Розанова, хранящегося в отделе рукописей Российской государственной библиотеки (ОР РГБ). Акцентировано внимание на двойственности позиций не только В.В. Розанова, но и самих критиков, затеявших диспут. Цель исследования - на основе неизвестных ранее архивных источников, представленных в статье, опровергнуть миф об отсутствии авторской редакторской работы со стороны философа над произведениями в жанре публищистики, доказать значимость этой работы для самого мыслителя. Именно В.В. Розанову принадлежит авторство термина «литературный террор». Рассмотрен лексический ряд зарождения этого понятия в текстах писателя. Статья подтверждает взгляд В.В. Розанова на недопу-

* Настоящая статья подготовлена в рамках исследовательского проекта Российской государственной библиотеки. 
стимость политизащии его творческих работ. Освещаются личные мотивы в судьбе философа во время описанной газетно-журнальной полемики. Отвечая на обвинения в безнравственности, он утверждал неразделимость таланта и нравственных сил души литератора. При этом отмечается важность для В.В. Розанова понимания «мозаччности» состава культурных образований во всех видах творческого процесса. В статье даны ориентиры для детализации мировоззренческих основ, использованных литератором в его полемических выступлениях.

Ключевые слова: литературный террор, В.В. Розанов, полемика, П.Б. Струве, А.В. Пешехонов, черновые редакции, талант, безнравственность, мозаичность, философия творчества, мировоззрение, философия культуры, культура и личность.

Для цитирования: Ломоносов А.В. О литературном терроре (по материалам черновиков и неизданных статей В.В. Розанова) // Обсерватория культуры. 2019. Т. 16, № 1. С. 62-71. DOI: 10.25281/2072-3156-2019-16-1-62-71.

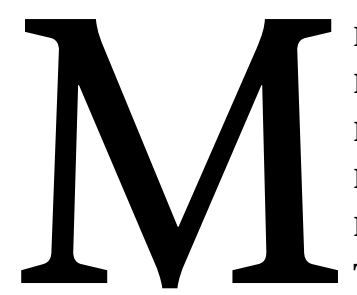

ногогранный, амбивалентный подход к решению проблем культурной и общественной жизни России великого русского мыслителя Василия Васильевича Розанова (1856-1919), гениальность которого признавалась еще современниками, до сих пор помогает в неординарном осмыслении важнейших исторических событий в нашей стране. Необычность и новизна их толкования были встречены в штыки основной частью либеральной интеллигенции, которая придерживалась в своих выступлениях принятых на тот момент партийных рамок. Одним из кардинальных моментов в понимании оригинальной мировоззренческой позиции В.В. Розанова стала его полемика с рядом левых журналистов в конце 1910 - начале 1911 года.

Возникла дискуссия по результатам издания его книги «Когда начальство ушло» (СПб., 1910). В сборник вошли репортажи и статьи периода общественных потрясений
1905-1906 годов. Литературным стремлением В.В. Розанова в те годы владели бурные события начала революции. Левых публицистов либеральных и радикально-демократических изданий возмутило то, что он разместил в сборнике подряд по хронологии создания статьи, писавшиеся как для правоцентристской газеты «Новое время», так и для либеральной газеты «Русское слово». Одни и те же факты представали с прямо противоположных сторон в произведениях журналиста «Нового времени» В.В. Розанова и газетного сотрудника «Русского слова» Варварина (псевдоним Розанова). Оппонентов публициста вывело из себя то, что он, совсем недавно призывавший к притеснению леворадикалов, издал тексты с хвалебными строками в честь освежающих ветров революции. Это посчитали образцом политической и нравственной беспринципности.

Ни один из крупных исследователей творчества В.В. Розанова не прошел мимо предъявленных ему обвинений и возникшей в результате этого дискуссии [1, с. 41; 2, с. 138; 3, с. 683].

Некоторые авторы, например философкультуролог И.В. Кондаков, считают В.В. Розанова вообще «родоначальником русского и мирового модернизма» [4, с. 60] и убеждены, что он полностью проявился в собственных текстах уже в самом начале литературного творчества. Необходимо лишь адекватно оценивать его способ мышления, который объяснялся им самим в принципиально противоречивых литературных трудах.

Именно этот образ мысли скандального для современников писателя послужил причиной бурной дискуссии с П.Б. Струве, К.И. Чуковским и А.В. Пешехоновым. Понимание значения разбираемой дискуссии для оценки мировоззрения В.В. Розанова невозможно без погружения в ее детали.

Первые упреки в адрес писателя были опубликованы в кадетской газете «Речь» от 24 октября 1910 года. Он обвинялся в полном безразличии к революционным страстям, сотрясавшим его соотечественников. Критик увидел в этом только грех и цинизм публициста, который сунулся со своей зевотой туда, где героически «жертвуют собой» [5, с. 172].

Общепризнанным инициатором нападок на B.B. Розанова из лагеря оппозиционной печа- 
ти принято считать известного общественного деятеля П.Б. Струве. Будучи автором первого публичного документа отечественных марксистов - «Манифеста Российской социал-демократической рабочей партии», он сам в итоге идейных исканий за год до выступления против В.В. Розанова пришел к осуждению радикальных методов борьбы и стал одним из вдохновителей антиреволюционного сборника «Вехи» (М., 1909).

В своем журнале «Русская мысль» (1910. Кн. 11) веховец П.Б. Струве продолжил нападки на В.В. Розанова. В статье «Большой писатель с органическим пороком» он был обвинен в цинизме, религиозном нигилизме и патологической безнравственности. Доказательством тому П.Б. Струве считал пренебрежительное и слишком художественное обращение писателя с фактическим материалом. В этом либеральному критику, апологету фактов с врожденно немецким педантизмом, безусловно, виделась «органически безнравственная и безбожная натура» оппонента [6, с. 275].

Особо подчеркнув блестящий литературный талант В.В. Розанова, ставшего основателем совершенно нового вида публицистики, синтезировавшей философско-политические мысли с обыденной реальностью, критик, при всех похвалах, задался риторическим вопросом: «А можно ли вообще пускать В.В. Розанова в “прогрессивную” печать?».

Публицист моментально реагировал на выпады в свой адрес. И здесь необходимо особо отметить, что отсутствие досконального анализа текстов его статей до сих пор остается белым пятном. В этом представляется главный недостаток всех предыдущих исследований по заявленной теме.

В начале ноября 1910 г. В.В. Розанов сам признавался в письме другу П.П. Перцову, что пребывает «в бешенстве от статьи Струве» $[7$, c. 115]. Чем же оно было вызвано и во что вылилось?

В отделе рукописей Российской государственной библиотеки (ОР РГБ) сохранилась масса черновых вариантов, редакций, разрозненных фрагментов ответов и даже неизвестных ранее законченных статей В.В. Розанова по обсуждаемой теме, отклоненных редакцией газеты «Новое время». А ведь он тщательно создавал о себе литературный миф, что никогда не правит своих статей, и неоднократно подчеркивал это в собственных произведениях. Я уже попытался оспорить это устоявшееся утверждение, опубликовав черновики его статей с вариантами авторской правки [8]. Обилие вариантов текста творческих материалов, увидевших свет в рамках 35-томного Полного собрания сочинений, выходящего в свет с 2014 г. [9], усилило сомнения в справедливости общего положения, что В.В. Розанов работал над текстом практически без правки [10].

Попытаемся разрешить эту загадку.

Возражая критикам, мыслитель приоткрыл завесу своей писательской кухни. Не раз и не два В.В. Розанов возвращался к обвинениям в противоречиях в своих текстах. Он пытался объяснить читателям специфику собственного метода мышления, показывая, что его различные мысли о каком-либо событии только в своей совокупности могут приблизить собеседника к общему пониманию истины. Лишь все многообразие мыслей художника создает полную картину. В реальном мире этот абсолют, как известно, пока недостижим. Поэтому можно созерцать лишь вершину айсберга, одну из представленных точек зрения. Из этого и напрашивался его парадоксальный вывод: единственный твердый принцип в жизни - это колебание, а истина предстает лишь «в колебании» [10, с. 413]. Свобода художника оказалась совершенно неприемлемой для железных принципов партийной публицистики в современной жизни постреволюционной России.

В.В. Розанов в этом случае был не так уж далек от марксистской методологии познания, наверняка знакомой П.Б. Струве, одному из первых российских марксистов.

Ранняя редакция первой статьи В.В. Розанова, отвечавшей на обвинения в безнравственности, носила показательное название «Политики в литературе». Оно вполне определяло суть обсуждаемой проблемы. В гранках работа носила название «Литературные и нравственные афоризмы». По выходе заголовок обрел уже некую размытость «Литературные и политические афоризмы (Ответ К.И. Чуковскому и П.Б. Струве)» (Новое время. 1910. 25, 28 нояб., 9 дек.) [10].

Анализ обширной черновой правки нескольких редакций статьи свидетельствует 
о борьбе В.В. Розанова с эмоциональным накалом распиравших его чувств в момент работы над текстом полемического ответа. Например, фраза «нетерпеливо до боли» сглажена до «нетерпеливо хочу» [10, с. 413].

Для того чтобы избежать повторных обвинений со стороны оппонентов в равнодушии при обсуждении вопроса об отношении к революции, он снимает свой предыдущий текст и переносит предмет дискуссии в более широкую область - границы бытия человеческой души.

Если в черновой редакции В.В. Розанов пишет, что, отвечая на вопрос о революции, ему или спать хочется, или разразиться «гомерическим хохотом, заскрежетать зубами или заплакать» $[11$, л. 8], то в публикации он уже переходит на уровень обсуждения вездесущности человеческой души. Критикам указано на абсолютное непонимание элементарных вещей обыденного религиозного сознания.

Еще в 1892 г. В.В. Розанов в полемике с Н.К. Михайловским отстаивал творческий принцип «мозаичности культуры». Уже тогда мыслитель вызвал в свой адрес град упреков в оправдании беспринципности. Он доказывал, что идеал мировой гармонии не просто недостижим и иллюзорен, но и крайне опасен. В социальной жизни стремления к его реализации приводят к неизбежному массовому насилию, чему учат любые попытки построить рай на земле. Мир, согласно философу, в своей основе не просто многообразен, как справедливо заметил И.В. Кондаков, но «еще и насильно лишен изначальной цельности - сломан, раздроблен, искусственно запутан, а потому - безысходно трагичен» $[4$, с. 68].

Гораздо большее значение для В.В. Розанова в качестве ответа своим оппонентам на обвинения, вызвавшие столь бурный общественный резонанс, имела статья «Литературный террор» (Новое время. 1911. 12 янв.). Она стала своеобразной общественной декларацией писателя как художника, имеющего право на абсолютное свободное самовыражение внеполитических программ и партийных предпочтений.

В январской статье 1911 г. В.В. Розанов обвинил социал-демократов в установлении настоящего террора в русской литературе, главным средством борьбы которого было лишение писателя чести, предание его позору в глазах общественного мнения. Именно с момента выхода из печати статей П.Б. Струве и критиков левого лагеря началась систематическая травля В.В. Розанова со стороны всех оппозиционных органов печати.

Возражения В.В. Розанова рождались в столь же усиленных творческих потугах, как и предыдущая статья к политикам от литературы. До появления статьи в печати на свет появилось не менее двух ее редакций. В первоначальном варианте статья имела иное название - «Террор” в литературе» $[12$, л. 1], переносящее акцент на ключевое слово в обсуждаемой проблеме.

Напомним, что П.Б. Струве перед обвинением оппонента в безнравственности сделал реверанс, объявив его талантливым писателем. На что В.В. Розанов отвечал своим творческим кредо: «Талант и есть преобразование в слово нравственных сил души... до абсолютного совпадения» $[13$, с. 20]. Множество похвал в свой адрес со стороны П.Б. Струве В.В. Розанов отвергал и позднее по одной единственной причине: они вращались вокруг недостижимого для П.Б. Струве пункта - «психологичность самого языка» $[14$, с. 355]. Бесталанным людям мыслитель решительно отказывал в звании достойного политика. К ним он в то время причислял все радикальные политические образования.

Действуя в давно известной системе подавления инакомыслия, решительно настроенная общественность усмирила всякий протест против себя, используя массовую периодическую печать.

Статью о терроре в периодике В.В. Розанов начал с упоминания литераторов, сочувствовавших социал-демократам, - А.М. Горького и Н.М. Минского. Но даже они, по словам автора, презирали за бездарность и отсутствие таланта большевика-беллетриста А.А. Богданова. В 1908 г. он издал свой первый фантастический роман-утопию «Красная звезда» о построении идеального социального строя на Марсе. Художественные фантазии вице-лидера большевиков имели реальные примеры в истории, судьбах его соотечественников на территории бывшей Российской империи - в системе Пролеткульта. Она предполагала полное до основания разрушение культуры старого мира в бес- 
пощадном пламени классовой борьбы. А что было и что стало затем с носителями отечественной культуры, все хорошо помнят.

Большое, а возможно и ключевое место в статье В.В. Розанова занимает именно определение этических составляющих таланта. Оно основано прежде всего на принципах неотделимости понимания для талантливого писателя честности и правды. Сравнивая эти нравственные категории со значением красоты для женщины, публицист, редко шлифовавший ранее свои тексты, тщательно подбирает нужное слово. Если в первой редакции для него девичья красота «то же, что для писателя “честность”, “правда” $[12$, л. 1], то во второй - «что для женщины “красота лица”, то ... для писателя есть оценка его нравственной личности как человека, его человеческой и вместе непременно писательской правды. Честь. Суть» $[12$, л. 5]. В печати же характеристика нравственной личности писателя сравнивается с человеческой искренностью и правдой [13, с. 19].

Интересно отметить, насколько это было важно для автора. Мыслитель дает собственный ответ на важнейший в любом творческом деле вопрос, выделяя слово «честность» прописными буквами. Этого не было в первоначальной редакции.

В.В. Розанов указал на давно устоявшийся в современной исторической науке факт о связи П.Б. Струве и его окружения с революционным движением. Бывший марксист через периодическую печать подталкивал Россию к революции. «Нововременец» вернул «освобожденцу» ярлык «двурушника», навешанный на него газетчиком А.В. Пешехоновым. П.Б. Струве, как известно, будучи одним из лидеров партии кадетов, не брезговал публиковать в редактируемом им журнале «Русская мысль» статьи социал-демократической направленности.

Возражения В.В. Розанова в печати П.Б. Струве не оставил без внимания и отреагировал очередными нападками в заметке «Жестокая поговорка и извращенная психология» (Русская мысль. 1911. Кн. 1. С. 182-186). Формальным поводом для нее был ответ А.В. Пешехонову, поддержавшему П.Б. Струве в осуждении В.В. Розанова [15].
Раздраженный В.В. Розанов написал ответ и на этот выпад. Текст сохранился в двух редакциях в рукописном автографе в ОР РГБ: «Двое убогоньких» [16] и «Убогонькие в истории» [17]. При жизни автора статья так и не вышла. Из-за резкости тона собственного выступления В.В. Розанов забрал ее из редакции, оставив пояснение в списке библиографии: «Сам взял назад» [18]. Впервые была опубликована мной в рамках 30-томного Собрания сочинений [14].

Признав и декларируя, что именно П.Б. Струве дал первый толчок к широкому обсуждению его общественной позиции в печати, В.В. Розанов сместил акцент содержания заметки последнего. П.Б. Струве выступил с осуждением эпигонского критиканства со стороны А.В. Пешехонова в адрес так называемого разоблачения В.В. Розанова и прямо заявил, что получил тягостное впечатление от этого выступления. А.В. Пешехонов, как известно, самодовольно ответил, что не только не общался с В.В. Розановым, а даже «готов был плюнуть ему в лицо и за прошлое, и за настоящее, и за будущее. Злая радость» [19]. П.Б. Струве же указал в заметке на свое несогласие со злорадством критика.

Самые обидные для себя выражения со стороны П.Б. Струве В.В. Розанов вынес в качестве одного из множества эпиграфов к своей статье: «Можно бы и извинительно Розанову плюнуть в лицо. Но мое христианское чувство не дозволяет этого» [13, с. 18]. Используя старый риторический прием, он это обвинение перенес по адресу самого П.Б. Струве, настаивая, что его хотят «превратить в плевательнииу» [20, c. 22]. На что редактор «Русской мысли» возмутился искажением не только своих слов, но и подменой общего смысла цитаты. В.В. Розанов вынужден был отвечать новым письмом в редакцию своей газеты «Новое время». Там он опять же отметил лишь вспомогательную роль А.В. Пешехонова по отношению к публичной травле в свой адрес, считая, что искажение лица честного писателя началось в нашей периодике именно с П.Б. Струве.

Вскрывал В.В. Розанов и некое двурушничество самого редактора «Русской мысли». Философ припомнил эпизод, когда он повторил П.Б. Струве его собственные слова, осу- 
ждавшие радикализм Н.Г. Чернышевского и Д.И. Писарева в печати. И после этого апостол либеральной печати обвинил В.В. Розанова в предательстве всего освободительного движения и во враждебности ко всей прогрессивной прессе.

Интересна оценка материальной стороны вопроса. В ответ на пешехоновское обвинение в двурушничестве В.В. Розанов заявил, что просто своим честным писательским трудом содержал многочисленное семейство. Революционные же публицисты, по его убеждению, напротив, всегда существовали за чей-то чужой счет, будь то частные лица или иностранные державы.

Любопытно, что к моменту выхода из печати ответа на обвинения А.В. Пешехонова в философе проснулся внутренний цензор и саморедактор. Начало рукописи статьи, вылившееся в некий чисто розановский памфлет с метафорами из альковных историй, он сократил всего до одного предложения. Печать увидела лишь фраза, сравнивавшая поведение левых критиков с ревнивой старой любовницей. В стиле национальных предпочтений своей газеты B.B. Розанов заявлял в черновой редакции от лица простого читателя из народа: «Никак мужичек не может поверить, что Карл Маркс из Берлина есть тот “Иван Царевич”, который освободит его от всяких бед и напастей. Ни во Франсуа Фурье не может поверить. Такой невежда: и французское и немецкое отвергает.

“Отвергнутая” дева разъярена: бросается то на Пушкина ... то на Достоевского, которого уважают больше, чем Шпильгагена, то на Тютчева, которого предпочитают Гейне; бросалась лет 50 на Толстого, которого ставили выше Жорж Занд...» [21, л. 3].

Долгое время пребывая в процессе внутренней дискуссии с означенными оппонентами, три года спустя В.В. Розанов задался вопросом о причинах столь резких выступлений против себя в наиболее тяжелый период жизни. Он показал читателю, что с ним происходило на этом драматичном этапе. Во-первых, в самый пик газетно-журнальных нападок на В.В. Розанова ему пришлось бороться за жизнь жены, с которой случилась частичная парализация. Тогда же оставил свои дела его газетный попечитель
А.С. Суворин, спасший литератора в свое время от прозябания и неустроенности. Тяжелейшие внутренние переживания дали и некий лейтмотив всем его текстам: «Оставьте же меня в покое» $[14$, с. 20$]$.

Именно в это время В.В. Розанов пытается публично сформулировать ценностные ориентиры и ищет примирения с православной церковью. Ему открылось все уродство политических газетных баталий перед вечными жизненными проблемами: страхом смерти и вечного расставания с любимым человеком. В жестокой словесной перебранке ему даже привиделись признаки нечистой силы.

Обращаясь к своим обвинителям, В.В. Розанов упрекал их в бесчеловечности и недемократизме, так как они набросились на него в период тяжелейших жизненных испытаний и совершенно не учитывали, что писатель нелегким трудом газетного журналиста содержал своих многочисленных родных и близких. Только тот литератор мог, по мнению В.В. Розанова, называться мудрецом, который ни в чем не разделяется с остальным народом и рассматривает свое литературное или философское творчество как простую работу.

По завершении столь чувствительной для себя полемики писатель протянул своим оппонентам руку и призывал их к примирению, еще раз напомнив им о скрытых мотивах его запальчивости: «Конечно, формально и, “по признакам судя”, они не могли иначе судить, но им следовало задержаться из осторожности, сказав себе: “Тут не все ясно” $[22$, с. 246].

К чести В.В. Розанова следует отметить, что абсолютно все его оппоненты, вызвавшие столь бурный эмоциональны взрыв, не только были им прощены, но и получили в этом публичное признание в его печатных работах. А им, учитывая обретенный писателем новый стиль исповедально-уединенной прозы, нельзя было не поверить.

К.И. Чуковского в книге «Опавшие листья. Короб второй и последний» В.В. Розанов похвалил за то, что ему единственному из нападавших критиков удалось дать определение его истинной натуре и темпераменту [23, с. 303].

Вызывавший некогда резкое пренебрежение А.В. Пешехонов предстал как «последняя значащая фигура с<оциал>-д<емократии >. Од- 
нако значучесть эта заключается единственно в чистоте его» [24, с. 32].

П.Б. Струве удостоился гораздо большего количества похвал и положительных характеристик. Приведем лишь одну. «Сложная и в высшей степени интересная судьба Струве все более и более склоняет его в сторону, в которую он никогда не хотел ходить, в которой он никогда не думал бы. Дело в том, что среди всяческой трухи экономических и политических воззрений в душу залетело одно ангельское существо: любовь к России» [25, с. 40].

Спустя годы, анализируя сам факт истории своего параллельного сотрудничества в газетах разной политической направленности, вызвавший столь бурное общественное осуждение, В.В. Розанов все еще искал ответ на этот столь взволновавший всех вопрос. Принимая душевную гармонию в отношении политических ориентиров «Нового времени» и целый ряд несогласий с руководством либерального издания «Русское слово», мыслитель в то же время отмечал, что был совершенно искренен во всех своих выступлениях в прессе. Признав в итоге за собой, хотя и частично, некое «двурушничество» по отношению к политическим органам печати и не одобряя их эпатажных выпадов в адрес оппонентов, он пытался еще и еще раз объяснить, что, став для левых газет persona non grata, был всегда абсолютно честен и искренен перед самим собой и перед Богом.

В результате рассмотренной полемики, благодаря привлечению неизвестных ранее черновых текстов работ В.В. Розанова, показана значимость для мыслителя возникшего противостояния с леволиберальными, социал-демократическими представителями печати, носителями устойчивых общественнополитических схем в литературном процессе. Благодаря рассмотренной дискуссии становится более понятной система мировоззрения В.В. Розанова, содержащая широкие перспективы для альтернативного выбора путей развития и познания. Она указывает на определенное предощущение мыслителем уже в начале XX в. рассыпания целостной модели мира среди носителей традиционных культурных ценностей, отразившегося как в литературных, так и в политических процессах, его окружавших и еще грядущих.

\section{Список источников}

1. Сукач В.Г. Василий Васильевич Розанов : биографический очерк : библиография 18862007. Москва : Прогресс-Плеяда, 2008. 220 с.

2. Простаков О.Г. П.Б. Струве и В.В. Розанов // Мир источниковедения : сборник. Москва ; Пенза, 1994. С. 136-139.

3. Фатеев В.А. Жизнеописание Василия Розанова. [Изд. 2-е, испр. и доп.]. Санкт-Петербург : Пушкинский Дом, 2013. 1054 с.

4. Кондаков И.В. Русская культура-post: у истоков культурного самосознания // Энтелехия. 2007. № 15 . С. $60-86$.

5. Чуковский К.И. Открытое письмо В.В. Розанову // Собр. соч. : в 15 т. Т. 7 / [сост. и коммент. Е. Чуковской]. Москва : Терра-Книжный клуб, 2001. С. $171-178$.

6. Струве П.Б. Большой писатель с органическим пороком // П.Б. Струве. Patriotica. Политика, культура, религия, социализм / вступ. ст. и примеч. В.Н. Жукова. Москва : Республика, 1997. C. $270-278$.

7. Из эпистолярного наследия П.П. Перцова / публ. Г.В. Давыдовой // Энтелехия. 2004. № 9. С. $112-117$.

8. Ломоносов А.В. Неизвестный В.В. Розанов // Записки отдела рукописей / Российская государственная библиотека. Вып. 53. Москва: Пашков дом, 2008. С. 455-487.

9. Розанов В.В. Полн. собр. соч. : в 35 т. Серия «Литература и художество» : в 7 т. Т. 1-7 / под общ. ред. А.Н. Николюкина. Санкт-Петербург : Росток, 2014-2017.

10. Розанов В.В. Литературные и политические афоризмы : (Ответ К.И. Чуковскому и П.Б. Струве) // Собр. соч. : в 30 т. [Т. 20]. Загадки русской провокации. Статьи и очерки 1910 г. / под общ. ред. А.Н. Николюкина. Москва : Республика, 2005. С. 412-423.

11. Розанов В.В. Фрагменты статей на литературные темы // Отдел рукописей Российской государственной библиотеки. Ф. 249 (В.В. Розанов). Картон 6. Ед. хр. 14. Л. 1-16.

12. Розанов B.B. «Террор» в литературе // Отдел рукописей Российской государственной библиотеки. Ф. 249 (В.В. Розанов). Картон 6. Ед. хр. 6. Л. 1-11.

13. Розанов В.В. Литературный террор // Собр. соч. : в 30 т. [Т. 21]. Террор против русского национализма. Статья и очерки 1911 г. Москва : Республика, 2005. С. 18-21. 
14. Розанов В.В. Убогонькие в истории // Собр. соч. : в 30 т. [Т. 21]. Террор против русского национализма. Статья и очерки 1911 г. Москва : Республика, 2005. С. 353-357.

15. Пешехонов А.В. Бесстыжее светило, или Изобличенный двурушник // Русские ведомости. 1910. 2 дек.

16. Розанов В.В. Двое убогоньких... // Отдел рукописей Российской государственной библиотеки. Ф. 249 (В.В. Розанов). Картон 5. Ед. хр. 23. Л. $1-3$.

17. Розанов В.В. Убогонькие в истории // Отдел рукописей Российской государственной библиотеки. Ф. 249 (В.В. Розанов). Картон 6. Ед. хр. 7. Л. $1-5$.

18. Цветков С.А. Библиография произведений В.В. Розанова с 1909 по 1910 гг. // Отдел рукописей Российской государственной библиотеки. Ф. 249 (В.В. Розанов). Картон 11. Ед. хр. 11. Л. 293.

19. Струве П.Б. Жестокая поговорка и извращенная психология : (На разные темы) // Русская мысль. 1911. Кн. 1. С. 182-186.

20. Розанов В.В. Письмо в редакцию // Собр. соч. : в 30 т. [Т. 21]. Террор против русского национа- лизма. Статья и очерки 1911 г. Москва : Республика, 2005. С. 21-23.

21. Розанов В.В. Фрагменты статей на политические, религиозные, философские темы // Отдел рукописей Российской государственной библиотеки. Ф. 249 (В.В. Розанов). Картон 6. Ед. хр. 15. Л. $1-29$.

22. Розанов В.В. Мимолетное. 1914 год // Собр. соч. : в 30 т. [Т. 8]. Когда начальство ушло... / под общ. ред. А.Н. Николюкина. Москва : Республика,1997. С. 193-596.

23. Розанов В.В. Опавшие листья. Короб второй и последний // Уединенное / под общ. ред. А.Н. Николюкина. Москва : Политиздат, 1990. С. 203-390 (Серия «Мыслители ХХ века»).

24. Розанов В.В. Уединенное // Уединенное / под общ. ред. А.Н. Николюкина. Москва : Политиздат, 1990. С. 21-86 (Серия «Мыслители XX века»).

25. Розанов В.В. Струве о духовном сословии и духовной школе // Собр. соч. : в 30 т. [Т. 24]. В чаду войны. Статья и очерки 19161918 гг.» / под общ. ред. А.Н. Николюкина. Москва : Республика ; Санкт-Петербург : Росток, 2008. С. 40-43.

\section{On Literary Terror (Based on the Materials of V.V. Rozanov's Drafts and Unpublished Articles)}

\author{
Aleksey V. Lomonosov \\ Russian State Library, 3/5, Vozdvizhenka Str., \\ Moscow, 119019, Russia \\ ORCID 0000-0001-9755-8649; SPIN 3533-2784 \\ E-mail: lomonosov-1962@yandex.ru
}

\begin{abstract}
The article presents the views of experts on the specifics of V.V. Rozanov's literary discussions. It highlights the features of the thinker's polemics with P.B. Struve and his colleagues about the boundaries of the party framework in the course of public statements in late 1910 - early 1911. The most vivid details of disputes on the previously mentioned topic are noted. This is evidenced by citation of various draft ver-
\end{abstract}

sions of manuscript materials from V.V. Rozanov's archive, stored in the Manuscripts Department of the Russian State Library. The article focuses on the duality of the positions not only of V.V. Rozanov, but also of the critics who started the dispute. On the basis of previously unknown archival sources presented in the article, the study aims to refute the myth that the philosopher was never engaged in author's editing of works in the genre of journalism, and to prove the importance of this work for the thinker. It was V.V. Rozanov who introduced the term "literary terror". There is considered the lexical series of the origin of this concept in the writer's texts. The article confirms V.V. Rozanov's view on the inadmissibility of politicization of his creative works. Personal motives in the philosopher's fate during the described journalistic polemics are revealed. Responding to accusations of immorality, he claimed the inseparability of talent and moral forces of a literary person's soul. There is also noted that it was important for 


\section{V.V. Rozanov to understand the "mosaic" compo- sition of cultural formations in all types of creative process. The article provides guidelines for detai- ling the ideological foundations used by the writer in his polemical speeches.}

Key words: literary terror, V.V. Rozanov, polemics, P.B. Struve, A.V. Peshekhonov, drafts, talent, immorality, mosaics, philosophy of creativity, worldview, philosophy of culture, culture and person.

Citation: Lomonosov A.V. On Literary Terror (Based on the Materials of V.V. Rozanov's Drafts and Unpublished Articles), Observatory of Culture, 2019, vol. 16, no. 1, pp. 62-71. DOI: 10.25281/2072-3156-2019-16-1-62-71.

\section{Acknowledgements.}

This article is written as a part of the research project of the Russian State Library.

\section{References}

1. Sukach V.G. Vasilii Vasil'evich Rozanov: biograficheskii ocherk: bibliografiya 1886-2007 [Vasily Vasilyevich Rozanov: Biographical Essay: Bibliography 1886-2007]. Moscow, Progress-Pleyada Publ., 2008, 220 p.

2. Prostakov O.G. P.B. Struve and V.V. Rozanov, Mir istochnikovedeniya: sbornik [The World of Source Studies: collection]. Moscow, Penza, 1994, pp. 136139 (in Russ.).

3. Fateev V.A. Zhizneopisanie Vasiliya Rozanova [Biography of Vasily Rozanov]. St. Petersburg, Pushkinskii Dom Publ., 2013, 1054 p.

4. Kondakov I.V. Russian Culture-Post: At the Origins of Cultural Identity, Entelekhiya [Entelechy], 2007, no. 15 , pp. 60-86 (in Russ.).

5. Chukovsky K.I. Open Letter to V.V. Rozanov, Sobr. soch.: $v 15$ t. T. 7 [Collected Works: in 15 volumes. Volume 7]. Moscow, Terra-Knizhnyi Klub Publ., 2001, pp. 171-178 (in Russ.).

6. Struve P.B. A Great Writer with an Organic Blemish, P.B. Struve. Patriotica. Politika, kul'tura, religiya, sotsializm [P.B. Struve. Patriotica. Politics, Culture, Religion, Socialism]. Moscow, Respublika Publ., 1997, pp. 270-278 (in Russ.).

7. From P.P. Pertsov's Epistolary Heritage, Entelekhiya [Entelechy], 2004, no. 9, pp. 112-117 (in Russ.).

8. Lomonosov A.V. Unknown Rozanov, Zapiski otdela rukopisei [Notes of the Manuscripts Depart- ment]. Moscow, Pashkov Dom Publ., 2008, issue 53, pp. 455-487 (in Russ.).

9. Rozanov V.V. Poln. sobr. soch.: v 35 t. Seriya "Literatura i khudozhestvo": v 7 t. T. 1-7 [Complete Works: in 35 volumes. "Literature and Art" Series: in 7 volumes. Volumes 1-7]. St. Petersburg, Rostok Publ., 2014-2017.

10. Rozanov V.V. Literary and Political Aphorisms (A Response to K.I. Chukovsky and P.B. Struve), Sobr. soch.: $v 30$ t. Zagadki russkoi provokatsii. Stat'i $i$ ocherki $1910 \mathrm{~g}$. [Collected Works in 30 volumes. The Mystery of Russian Provocation. Articles and Essays of 1910]. Moscow, Respublika Publ., 2005, pp. 412-423 (in Russ.).

11. Rozanov V.V. Fragments of Articles on Literary Topics, Otdel rukopisei Rossiiskoi gosudarstvennoi biblioteki [Manuscripts Department of the Russian State Library], coll. 249 (V.V. Rozanov), carton 6, item 14, pp. 1-16 (in Russ.).

12. Rozanov V.V. "Terror" in Literature, Otdel rukopisei Rossiiskoi gosudarstvennoi biblioteki [Manuscripts Department of the Russian State Library], coll. 249 (V.V. Rozanov), carton 6, item 6, pp. 1-11 (in Russ.).

13. Rozanov V.V. Literary Terror, Sobr. soch.: $v 30$ t. Terror protiv russkogo natsionalizma [Collected Works: in 30 volumes. Terror against Russian Nationalism]. Moscow, Respublika Publ., 2005, pp. 18-21 (in Russ.).

14. Rozanov V.V. Wretched Ones in History, Sobr. soch.: $v 30 t$. Terror protiv russkogo natsionalizma [Collected Works: in 30 volumes. Terror against Russian Nationalism]. Moscow, Respublika Publ., 2005, pp. 353-357 (in Russ.).

15. Peshekhonov A.V. A Shameless Star, or an Unmasked Double-Dealer, Russkie vedomosti [Russian Bulletin], 1910, December 2 (in Russ.).

16. Rozanov V.V. Two Wretcheds... Otdel rukopisei Rossiiskoi gosudarstvennoi biblioteki [Manuscripts Department of the Russian State Library], coll. 249 (V.V. Rozanov), carton 5, item 23, pp. 1-3 (in Russ.).

17. Rozanov V.V. Wretched Ones in History, Otdel rukopisei Rossiiskoi gosudarstvennoi biblioteki [Manuscripts Department of the Russian State Library], coll. 249 (V.V. Rozanov), carton 6, item 7, pp. 1-5 (in Russ.).

18. Tsvetkov S.A. Bibliography of V.V. Rozanov's Works from 1909 to 1910, Otdel rukopisei Rossiiskoi gosudarstvennoi biblioteki [Manuscripts Department 
of the Russian State Library], coll. 249 (V.V. Rozanov), carton 11, item 11, p. 293 (in Russ.).

19. Struve P.B. The Cruel Saying and the Perverted Psychology (On Different Topics), Russkaya mysl' [Russian Thought], 1911, book 1, pp. 182-186 (in Russ.).

20. Rozanov V.V. Letter to the Editor, Sobr. soch.: $v 30$ t. Terror protiv russkogo natsionalizma [Collected Works: in 30 volumes. Terror against Russian Nationalism]. Moscow, Respublika Publ., 2005, pp. 21-23 (in Russ.).

21. Rozanov V.V. Fragments of Articles on Political, Religious, Philosophical Topics, Otdel rukopisei Rossiiskoi gosudarstvennoi biblioteki [Manuscripts Department of the Russian State Library], coll. 249 (V.V. Rozanov), carton 6, item 15, pp. 1-29 (in Russ.).
22. Rozanov V.V. Fleeting. 1914, Sobr. soch.: $v 30$ t. Kogda nachal'stvo ushlo... [Collected Works: in 30 volumes. When the Bosses Are Gone...]. Moscow. Respublika Publ., 1997, pp. 193-596 (in Russ.).

23. Rozanov V.V. Fallen Leaves. The Box Is the Second and Last, Uedinennoe [Secluded]. Moscow, Politizdat Publ., 1990, pp. 203-390 ("Mysliteli XX veka" Series) (in Russ.).

24. Rozanov V.V. Secluded, Uedinennoe [Secluded]. Moscow, Politizdat Publ., 1990, pp. 21-86 ("Mysliteli XX veka” Series) (in Russ.).

25. Rozanov V.V. Struve on the Clergy and Spiritual School, Sobr. soch.: $v 30 t$. V chadu voiny [Collected Works: in 30 volumes. In the Fumes of War]. Moscow, Respublika Publ., St. Petersburg, Rostok Publ., 2008, pp. 40-43 (in Russ.).

\section{НОВИНКА}

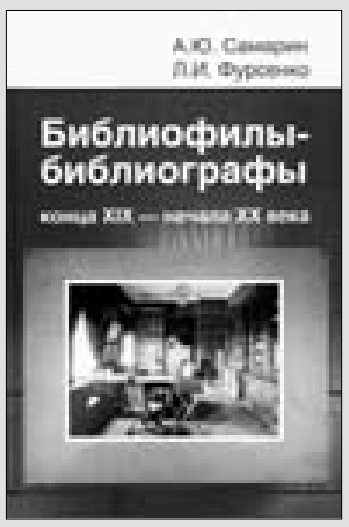

Самарин А.Ю.,Фурсенко Л.И.Библиофилы-библиографы конца XIX - начала XX века (П.К. Симони, Д.В. Ульянинский, Н.Н. Орлов) : монография. Москва : МИК, 2019.156 с.

Книга посвящена трем выдающимся библиофилам-библиографам (П.К. Симони, Д.В. Ульянинскому, Н.Н. Орлову), чья активная деятельность протекала в России В конце XIX - первой трети XX века. В научный оборот вводятся автобиографические и мемуарные материалы, представлены полные библиографии их трудов и публикаций о жизни и творчестве этих замечательных книжников.

Первый раздел посвящен члену-корреспонденту АН СССР Павлу Константиновичу Симони (1859-1939). Среди его научных интересов были: фрилологическое изучение памятников славянской и древнерусской письменности, публикация и анализ фольклорных произведений, история издательского дела и книжной торговли, палеография, библиография, вспомогательные исторические дисциплины и др. П.К. Симони собрал библиотеку, включавшую около 12 тысяч томов, оставил большое научное наследие, которое состоит как из опубликованных трудов (более 100), так и отложившихся в архиве ученого материалов. Во втором разделе помещены материалы о Дмитрии Васильевиче Ульянинском (1861-1918). Член-корреспондент АН СССР П.Н. Берков писал о нем: «Особое место в истории русского библиосильства и библиофильской литературы начала XX века занимает Дмитрий Васильевич Ульянинский <...> Его называли “поэтом книги”, его библиотеку - “дворцом книги”, в московских библиофильских кругах он считался главою русских библиофилов начала XX века...”

Третий раздел рассказывает о Николае Николаевиче Орлове (1898-1965), активнейшем участнике библиографической и библиофильской жизни 1920-х — начала 1930-х годов. Круг его интересов был очень широк: экслибрисы и литература о них, деятельность Русского библиографического общества при Московском университете (где он много лет был секретарем) и его история. Н.Н. Орлову принадлежат библиографические указатели современной ему литературы по книжному делу, библиотековедению, библиографии, книжной торговле.

Издание можно приобрести в книжных магазинах «Москва», «Фаланстер», а также в интернет-магазинах и в издательстве.

Справки по телефону: +7 (916) 6768104 